\title{
'No Thanks': a Socio-Semiotic Approach
}

\author{
Anita Fetzer (Stuttgart)
}

\begin{abstract}
This contribution argues for a socio-semiotic approach to natural-language communication which focuses on the connectedness between linguistic code and social and sociocultural practice. Section 1 investigates natural language communication with regard to propositional, interpersonal and interactional meaning from both code and inference-model viewpoints. The results of this discussion are accommodated in the redefinition of two of the most important premises of pragmatics, i.e. rationality and intentionality. In section 2 , the interdependence of culture, context and communication is analysed in the framework of ethnomethodology, in which the linguistic realization of an utterance and its degree of contextualization are examined with regard to encoding, decoding, inference and implicature. In section 3 the phenomenon of communicative strategy is analysed in a socio-semiotic framework and special attention is given to the speech acts of denial and rejection. Communicative strategies are defined within the framework of preference organization and classified with regard to their preferred and dispreferred modes of linguistic representation and interpretation. In section 4 , the results of the investigation of denials and rejections are systematized in the framework of the dialogue act of a plus/minus validity claim, which is based on Habermas' approach to communication (1987) and Halliday's functional interpretation of language (1996). In the conclusion, culture is defined as both a macro and a micro concept, and is created in and through the process of communication. Linguistic code and sociocultural practice are context-dependent by definition: they are anchored to linguistic contexts, which are embedded in sociocultural contexts, which are embedded in social contexts Thus, the macro concept of culture and its context-dependent manifestation as particular cultural values are reflected in particular communicative strategies which are interdependent on the presentation of self in everyday life (Goffman 1971).
\end{abstract}

\section{$1 \quad$ Introduction}

If communication consisted of the transmission of information only, both saying NO and interpreting the communicative meaning of NO would not cause any problems, since the communication act NO would present pure propositional information and thus could not cause any threat to the participants' face needs and face wants. ${ }^{1}$ In this setting there would be no indirect speech acts and no linguistic variation since both the encoding and decoding of

\footnotetext{
${ }^{1}$ Goffman (1971/74) presents a detailed investigation of face work. Brown \& Levinson's refined definition of rationality additionally accommodate their model person's face needs/ wants.
} 
messages would be based on the propositional code only. In other words, there would neither be any need for preferred and dispreferred modes for encoding communicative meaning, nor for conversational routine (Coulmas: 1981), and the linguistic code would be independent of a speech community's cultural and subcultural linguistic preferences. In such a framework the following exchanges would seem neither strange, nor marked, and would they cause any communication problems:

(1a) A: Do you want a cup of coffee?

B: No.

(1b) A: Willst du eine Tasse Kaffee?

B: Nein.

(2a) A: Can you tell me what time it is?

B: $\quad$ No.

(2b) A: Können Sie mir sagen, wie spät es ist?

B: Nein.

(3a) A: I like chocolate fudge cake/Van Morrison/Michael Douglas ... .

B: I Ion't like chocolate fudge cake/Van Morrison/Michael Douglas ... .

(3b) A: Ich mag Schokoladentorte/Van Morrison/Michael Douglas ... .

B: $\quad$ Ich mag Schokoladentorte/Van Morrison/Michael Douglas ... nicht.

(4a) A: Will the Labour government be able to deal with the crisis?

B: $\quad$ No.

(4b) A: Wird die Labour Regierung die Krise bewältigen können?

B: Nein.

[data fabricated]

Examples (1) to (4) represent marked responses ${ }^{2}$ in an Anglo-American or German setting, where the rejection of a prior speech act is generally not performed baldly on record. That is to say, they deviate from the speech communities' preferred modes of interaction, which require the non-acceptance of a prior assessment as in $(3 \mathrm{a} / \mathrm{b})$, of an offer as in $(1 \mathrm{a} / \mathrm{b})$, of a request as in $(2 \mathrm{a} / \mathrm{b})$, of a request for information as in $(4 \mathrm{a} / \mathrm{b})$ or of an invitation, not to be performed baldly on record, but they display instances of redressive action, e.g. I am so sorry, but ... , leider, somehow or schon. This 'additional language' refers to the participants' face needs/wants and has to be attributed the function of face work. To put it differently, the rejection of a prior speech act is generally not realized by the negative operators no/nein/kein or not/nicht only, but marked by 'additional language' which generally weakens the facethreatening force of the respective utterance. However, the degree of mitigation is not universal, but dependent on the sociocultural conventions of a speech community.

\footnotetext{
2 In a functional-grammar framework the dichotomy marked vs. unmarked is explicated as follows:

The marked format tends to be structurally more complex or larger, less frequent and thus cognitively more salient and cognitively more complex in terms of mental effort, attention demands, or processing time. (Givon 1993: 179; Levinson 1983: 307)
} 
The aim of my contribution no thanks: a socio-semiotic approach is to demonstrate that natural language communication has to be investigated with respect to both linguistic code and social and sociocultural practice. The socio-semiotics of the linguistic code and the respective linguistic system refer to the phenomenon of grammaticalization, e.g. syntax, morphology, tense or aspect, as well as to the semantics of concepts such as freedom, individual or metaphors we live by (Lakoff \& Johnson: 1980). Since the discursive meaning of the linguistic code is interdependent on the conventions of a specific speech community, it is interpreted differently by speakers of different languages. However, language as a sociosemiotic system should not only cover the linguistic system and linguistic code, but also investigate a speech community's communicative strategies, which are interdependent on the speakers' and hearers' employment of language in both private and public or institutional settings and therefore require a macro as well as micro approach.

To achieve my goal I will proceed as follows: In section 1 natural language communication is investigated with regard to propositional, interpersonal and interactional meaning from a code and inference-model viewpoint. The results of this discussion are accommodated for in the redefinition of one of the most important premises of pragmatics, i.e. rationality and intentionality. In section 2, the interdependence of culture, context and communication is analysed in the framework of ethnomethodology, in which the linguistic realization of an utterance, that is to say, its degree of contextualization, is investigated with regard to encoding, decoding, inference and implicature. In section 3 the phenomenon of communicative strategy is analysed in a socio-semiotic framework and special attention is given to the speech acts of denial and rejection. Communicative strategies are defined within the framework of preference organization and classified with regard to their preferred and dispreferred modes of linguistic representation and interpretation. In section 4, 'No thanks' revisited: the dialogue act 'plus/minus validity claim', the results of the investigation of denials and rejections are systematized in the framework of the dialogue act of a plus/minus validity claim, which is based on Habermas's approach to communication (1987) and Halliday's functional interpretation of language (1996). In the conclusion, culture is defined as both a macro and a micro concept, and is created in and through the process of communication. This inherently dynamic conception of culture is anchored to a dynamic conception of language which undergoes a constant process of grammaticalization. Against this background, language, viz. linguistic code and sociocultural practice, is contextdependent by definition. It is anchored to linguistic contexts, which are embedded in sociocultural contexts, which are embedded in social contexts. The macro concept of culture and its context-dependent manifestation as particular cultural values are thus reflected in particular communicative strategies which are interdependent on the presentation of self in everyday life (Goffman 1971).

\section{Propositional, interpersonal and interactional meaning: code or inference?}

Whenever people communicate, they do more than just exchange plain propositional information as they would do when they require a machine to perform certain actions. In linguistics and natural language communication there are numerous terms, which refer to this 
specifically humane domain of interaction, such as phatic and interpersonal communication, or tact and politeness (Watts et al. 1992). The main function of this type of communication does not consist of the transmission of propositional or referential meaning, but of information about the communication partners' interpersonal relationship. Speech act theorists were among the first linguists to point out the restrictions of a purely descriptive and truthconditional approach to natural language and therefore introduced different units of investigation, such as speech act, intention and cooperation, in order to account for natural language communication. One of their most radical premises states that linguistic meaning does not exist independently of speaker and hearer, and that is why the participants of a communicative encounter have been attributed a speaker, respectively hearer intention. In other words, communicative meaning is speaker-intended meaning and thus produced with a specific speaker intention. From an addressee viewpoint, communicative meaning is directed at one or more specific addressees who have been attributed a hearer intention in order to decode and/or infer the speaker-intended meaning. However, the attribution of intention is not a sufficient condition for explicating natural language communication, since speakers and hearers additionally have to cooperate in order to communicate. The basic unit of communication in the framework of speech act theory is the speech act, which is categorized with regard to an illocutionary and a propositional level. Since a speech act and its linguistic representation, i.e. an utterance, is produced with a speaker intention, the corresponding illocutionary point, illocutionary force and propositional content is also attributed an intentional status. In this framework speakers (and hearers) exchange propositional and illocutionary meaning, which is also reflected in the Gricean approach of logic and conversation (1975) and his concepts of literal, conventionally implicated and conversationally implicated meaning. Both speech act theory and Grice's 'logic and conversation' have had a tremendous impact on the investigation of language and linguistic performance, and the former has been applied to first and second-language-learning settings. ${ }^{3}$ In the following, the code and/or inference status of the examples (1) to (4) is investigated in speech-act and Gricean frameworks.

Speech exchange (1a) consists of two utterances produced by two different speakers A and B. But what speech acts are represented by these utterances? A speech act, by definition, consists of an illocutionary act and a propositional act. The propositional content of utterance A consists of the reference you and the predication (want + coffee), which is modified by the epistemic modality of volition [volition]. Yet, the propositional content of the utterance, i.e. the direct reference to the addressee you and the predication want coffee, does not give any specific information about its illocutionary status. Are there any illocutionary force indicating devices contained in the utterance? The propositional content is represented in the syntactic mode of a yes/no question and it is exactly this combination of 'direct reference to addressee', predication '[volition](coffee)' and yes/no question which triggers a process of inferencing

\footnotetext{
${ }^{3}$ There have been numerous projects which have investigated the interdependence of speech act realization and cultural context, e.g the project on Cross-Cultural Speech Act Realization Patterns, investigates the linguistic realization of the speech acts of apology and request in Hebrew, Danish, British English, American English, Australian English, German and Canadian French (Edmondson et al. 1984).
} 
resulting in the utterance's illocutionary point offer, whose illocutionary force is neither boosted nor attenuated. But does speaker A's communicative intention, i.e. her/him speakerintending the utterance Do you want a cup of coffee? to count as an offer, really have to be inferred by the hearer? More generally, does any illocutionary point, if it is not represented as an explicit performative, e.g. as I hereby offer you, have to be inferred by the hearer? Even though there is no explicit performative in exchange (1), the majority of the speakers of the Anglo-American, respectively German, speech communities would agree on (1) to represent a straight-forward offer, which is inferred from the combination of yes/no question, direct address of hearer and the respective predication modified by the epistemic modality of volition. Therefore, this specific combination has become a conventionalized formula for the linguistic representation of the illocutionary act of an offer. In general, these conventionalized indirect speech acts do not require any inference processes in order to retrieve their illocutionary points and therefore may be attributed to the linguistic code. To conclude, if an utterance does not contain an explicit performative and cannot be attributed to the paradigm of indirect conventionalized speech acts, its illocutionary point has to be inferred by the hearer. The response no of exchange (1) is as straightforward as the offer. Its illocutionary point is an unmitigated rejection, which may reject either the illocution or the propositional content of the prior speech act. If we analyse the utterance no in isolation, we cannot specify the propositional content of the rejection, i.e. the aspect of what is rejected - or whether anything is being denied at all. ${ }^{4}$ In the Gricean framework the utterances A and B adhere to the cooperative principle and the maxims of quality, quantity, relation and manner: the speakers do not say anything which they believe to be false, they do not say more than necessary for the current exchange, their contribution is relevant and the manner of representing the utterances is perspicuous, i.e. not obscure, not ambiguous, brief and orderly. Since there is no violation of a maxim, there is neither a generalized, nor a particularized conversational implicature. ${ }^{5}$

Speech exchange (2) consists of two different utterances produced by two different speakers, and like (1), it displays similar syntactical structures. Yet, do they have the same communicative functions? The propositional content of (2a) consists of the reference you and the predication (tell + time + now) modified by the epistemic modality [possibility]. Since the illocutionary point is not realized explicitly, the illocutionary meaning has to be inferred from the actual surface structure and possible illocutionary force indicating devices. The syntactic format of utterance $\mathrm{A}$ is a yes/no question, the propositional content consists of the direct reference to the hearer and a predication modified by the epistemic modality of possibility. The interaction of these points triggers an inference process, which results in the attribution of the illocutionary point of a request whose illocutionary force is attenuated by the epistemic modality of possibility, which transforms the direct request for information into a conventionalized indirect speech act of requesting. But how do speakers and hearers know

\footnotetext{
${ }^{4}$ Tottie(1991) differentiates between the rejection of an illocution and the denial of a proposition.

${ }^{5}$ Since neither speech act theory, nor the Gricean cooperative principle explicitly account for culture-specific modes of representing speaker-intended meaning, an analysis of the German examples in these frameworks follows the same patterns.
} 
whether an interrogative structure represents an offer or whether it represents a request for information? Speech act theory's answer to this question is that the illocutionary act has a conventional status and that is the reason why illocutionary meaning is conventional. The analysis of the response $N o$ in the framework of speech act theory is identical to the investigation of exchange (1). Yet a Gricean account of (2) follows a slightly different pattern since the request for information is triggered by the flouting of the maxim of manner. B's procedure of inferring the speaker-intended meaning, more precisely the speaker-intended conversational implicature, would go through the following steps: There is no reason for assuming that $\mathrm{A}$ has violated the cooperative principle, neither is there any reason for assuming that $\mathrm{A}$ has flouted quality, quantity and relation. Yet, the manner in which her/his utterance is produced is slightly ambiguous. However, there is still no reason to assume that s/he simply wants to know whether it was possible or not possible for B to tell the time. As a consequence, speaker $\mathrm{A}$ is in need of more information and therefore requests $\mathrm{B}$ to tell her/him the time. A Gricean analysis of response B follows the same pattern as in (1).

Speech exchange (3) also consists of two utterances produced by two different speakers. From a syntactic viewpoint, it represents a declarative structure, but what is its communicative function? The propositional content of the utterance I like chocolate fudge cake/Van Morrision/Michael Douglas consists of the speaker reference I and the predication (like + chocolate fudge cake). There is no explicit performative and therefore the illocutionary point of the utterance has to be inferred from the combination of a number of linguistic cues, such as syntactic format, i.e. declarative, and propositional content. As a result, utterance (4) represents a straightforward positive assessment with an unmitigated illocutionary force. The response I don't like chocolate fudge cake/Van Morrision/Michael Douglas deviates from the responses analysed so far, for it is not represented by the indexical no, but is more explicit about what is rejected. From a speech act viewpoint, this rejection may either represent the assertion of a negative assessment, i.e. I hereby assert that I do not like $X$, or it may represent the rejection of an assertion, i.e. I hereby reject the assertion that I like $X$. In the first case the illocutionary point of assessment remains unchanged and the proposition is denied, whereas in the second case the proposition remains unchanged and the illocution is rejected. A Gricean account of exchange (4) does not deviate from the way of reasoning of (1).

Speech exchange (4) consists of two utterances produced by two different speakers and its first part represents a yes/no question from a syntactic viewpoint. However, is its speakerintended meaning a request for information, an offer or an assessment? There is no explicit performative and its propositional content consists of the reference labour government and the predication $($ deal + crisis $)$ modified by the epistemic modalities [possibility, prediction]. As in the examples discussed so far, the syntactic structure functions as an illocutionary force indicating device and triggers a process of inferencing mapping the propositional content to a respective illocutionary point: this illocutionary point is a request for information whose illocutionary force is not mitigated. The response no follows the same patterns as in (1) and (2) and could, in principle reject the illocutionary force and/or the propositional content. However, is the speaker-intended meaning of (4) a request for agreement/disagreement only? A Gricean account of exchange (4) may follow the discussion of (1) and (3), but it may also 
accommodate the more general implicatures triggered by the requirements and constraints of discourse genres. For instance, if exchange (4) was an extract from a political interview, a request for information would not solely consist of a simple agreement or disagreement, but of agreement or disagreement and one or more additional accounts. Yet, if (4) was part of the speech event 'small talk' it would not necessarily trigger these discourse-specific implicatures, but a request to keep the conversation going. As a result, an investigation of communication in the framework of speech act theory allows for the differentiation between illocutionary and propositional meaning, whereas a Gricean account of communicative meaning may also accommodate discourse-specific implicatures. But how are interpersonal and interactional meanings accounted for?

In the framework of speech act theory the investigation of communicative meaning is restricted to the meaning of a single speech act. Should a speech act be represented in the indirect mode, the Gricean cooperative principle and the conversational implicature support the interpretative processes involved. In the former framework, interpersonal meaning is generally communicated by the illocutionary act, i.e. the illocutionary point and illocutionary force, whereas in the Gricean approach it is communicated by conversational implicatures. Generally, interpersonal meaning is part of a speech act's presuppositions and therefore hardly ever communicated baldly on record; it is only explicated in critical situations, such a a misunderstanding or a nonunderstanding. In other words, interpersonal meaning has to be inferred and can therefore only partly be accounted for by a code model. Interactional meaning gives information about a speech act's sequential status and therefore regulates its attribution to the initiating or responsive format. As is the case with interpersonal meaning, interactional meaning is hardly ever realized explicitly but has to be inferred from the propositional and/or illocutionary levels. Interactional meaning is only made explicit when there have been communication problems or if the discourse genre requires the interactants to specify their utterances' interactional statuses.

An investigation of interpersonal and interactional meaning requires a change of frame from speech act to discourse. However, discourse cannot be restricted to the phenomenon of text only but has to accommodate the extremely complex phenomena of context and contextualization as well as the subsystem(s) of cultural context(s). In the following section the socio-semiotics of culture is investigated in the framework of ethnomethodology and its premise of indexicality.

\section{Culture: an ethnomethodological approach}

Both culture and context represent extremely complex phenomena, which are difficult to define since they refer to our knowledge of the world and to our knowledge about the world. Some approaches to culture are carried out in a framework which is based on the dichotomies nature versus culture and chaos versus order (Sonesson 1989), while other investigations employ a paradigmatic approach based on mental, social and material artefacts (Posner 1989). However, these frameworks presuppose the existence of the phenomenon of culture, which is interpreted as something already given and thus as a result, and therefore do not explicitly 
discuss the question of how culture is created. In contrast to these rather static frameworks, the sociological field of ethnometholdology investigates the phenomenon of social reality from micro and macro perspectives by focussing on the investigation on these two realms as well as on their interactions. If we adapt the onion metaphor (Sperber and Wilson 1996) to the concepts of social action, social context and culture, a social action is surrounded by a cultural context which is surrounded by a social context. More precisely, the social role of an interviewer is a more general notion than the cultural role of a British or a Hebrew interviewer (Blum-Kulka 1987). As a consequence, the traditional notion of culture is embedded in the more general notion of social reality, and is therefore a necessary part of a speech community's social reality and social practice. Ethnomethodology introduced a radically different approach to the investigation of society, culture and context, and rejected the traditional definitions based on the macro realm only. Instead, they introduced the individual as a social actor who creates social reality through her/his social actions in the respective micro realms. This interdependence of social reality and social action is based on the concept of indexicality, more specifically on the indexicality of social actions. Thus the analysis of the social structures of everyday-life activities and everyday-life has become of importance not only for ordinary language philosophers such as H.P. Grice and J. Searle, but also for the social sciences. According to Harold Garfinkel, the pioneer of ethnomethodology, ethnomethodologists have to undertake "an investigation of the rational properties of indexical expressions and other practical actions as contingent ongoing accomplishments of organized artful practices of everyday life" (1994: 11). In this setting verbal and nonverbal communication, private as well as institutional or public discourse are of immense importance since the majority of everyday actions are constituted to some extent by these communicative exchanges. However, not only is the distinction between micro and macro levels of social actions of importance, but so is the nature of their interdependence and interaction. In the following the traditional and ethnomethodological approaches to socio-cultural context will be compared and discussed.

In a more traditional approach to communication, context is interpreted as a static phenomenon which is already given and therefore independent of the communicative encounter; there is neither any differentiation of context with regard to its micro and macro domains, nor is the phenomenon of culture contextualized. In contrast to these discreet settings, ethnomethodology interprets communication and communicative acts not only as indexical, but also as dynamic processes in which both context and socio-cultural context permanently interact with relevant constituents of the communicative encounter. As a consequence, communication, context and culture represent dynamic phenomena, which are anchored to the respective micro and macro domains. But how do context, culture and utterance interact? The premise of the indexicality of social actions requires a contextdependent investigation of verbal and nonverbal communication and their respective linguistic systems. Here, meaning is no longer an independent category but rather is the interpretative result of the interaction of an object and its immediate and more remote linguistic, sociocultural and social contexts. Thus, language is interdependent on both culture 
and context and cannot be represented by a discreet system. Instead, it has to be investigated in a socio-semiotic framework.

The ethnomethodological premise of the indexicality of social actions and the resulting interdependence between language, context and culture has relevant implications on the analysis of communication. In a traditional framework, communication is described as a speaker coding internal messages into external signals, which the hearer decodes. ${ }^{6}$ However, this setting neither accommodates the requirements resulting from the interaction of the systems of context, culture and language, nor the contextualization of the coding and decoding processes in general and the requirements of the respective socio-cultural contexts in particular. That is to say, not only do the production and interpretation of an utterance require the selection and attribution of appropriate contextual information to the message, but there is an additional requirement about whether the message is to be represented in the explicit and/or implicit modes. In the framework of speech act theory explicit utterances are referred to as direct speech acts, and their interpretation does not require the retrieval of a huge amount of contextual information, whereas implicit utterances depend strongly on their immediate contexts and generally require the retrieval of contextual information. Therefore, an utterance's degree of explicitness is interdependent on its degree of contextualization which is interdependent on language-external constraints, e.g. social power, degree of familiarity and gender, as well as on genre-specific constraints, e.g. face-to-face, monologue, dialogue, institutionalized participants' roles. However, the discussion of the interactive processes between the language system and context has not yet taken into consideration the specific interaction with the cultural system.

The results of intercultural-communication research ${ }^{7}$ show that the accommodation of language-external constraints on both language production and interpretation may be a universal phenomenon, but that their actual linguistic representation is definitely not universal. More precisely, the question whether a specific external factor is represented in the explicit or implicit modes is dependent on the speech community's communicative strategies and their preferred and dispreferred modes of representing social actions. Therefore, context and contextualization are not objective, but interdependent on the socio-cultural conventions of a speech community and its respective subcommunities. However, is it possible to use the terms of context and cultural context as synonyms? There is no clear-cut answer to this question, since the production and interpretation of context always depend on its medium and its respective cultural filters, but if context, culture and cultural context are investigated in an ethnomethodological setting and its premise of indexicality, context and culture represent macro phenomena and therefore entail the more specific concept of cultural context. ${ }^{8}$ Yet how

\footnotetext{
${ }^{6}$ In this setting, the psycholinguistic of processing, the pragmatic notions of inferring and interpreting, and the semiotic concept of decoding are used as 'functional synonyms'.

${ }^{7}$ Hall \& Hall (1994) differentiate between high context cultures and low context cultures and their respective modes of communication. Wierzbicka (1991) investigates a number of speech events and postulates different cultural scripts.

8 This argumentation only holds if culture and context are not used as synonyms. Should they be used as synonyms, the notion of cultural context would represent a tautology.
} 
do the macro realms of context and culture interact? If the dichotomy of nature vs. culture is valid, the two concepts have to be contained in a larger concept, which contains both of them. This larger concept is represented by the more general concept of context. But how do the phenomena of context, cultural context, contextualization and culture interact? Does culture also represent a dynamic concept? And does the dichotomy of micro vs. macro also apply to culture?

In an ethnomethodological framework, the "real" world is interpreted as organized activities of everyday life and as practical actions. Social and practical actions are characterized by the reflexibility (Garfinkel 1994: vii) of the following commonplace everyday activities: practical actions, practical circumstances, commonsense knowledge of social structures and practical sociological reasoning. However, practical actions do not exist as such but are performed by social actors who represent rational agents and therefore have to be able to account for their social actions:

(1) Whenever a member is required to demonstrate that an account analyses an actual situation, he invariably makes use of the practices of "et cetera", "unless" and "let it pass" to demonstrate the rationality of his achievement. (2) The definite and sensible character of the matter that is being reported is settled by an assignment that reporter and auditor make to each other that each will have furnished whatever unstated understandings are required. Much therefore of what is actually reported is not mentioned. (3) Over the time for their delivery accounts are apt to require that "auditors" be willing to wait for what will have been said in order that the present significance of what has been said will become clear. (4) Like conversations, reputations, and careers, the particulars of accounts are built up step by step over the actual uses of and references to them. (5) An account's materials are apt to depend heavily for sense upon their serial placement, upon their relevance of the auditor's projects, or upon the developing course of the organizational occasions of their use. (Garfinkel 1996: 3)

The social actors' ability to account for their social actions requires them to process and contextualize these actions. If the actions are interpreted as adhering to the cultural modes of verbal and nonverbal performance, they are attributed to the unmarked format and thus do not require any extra cognitive work. In this setting the "et cetera" strategy applies, that is to say, the micro actions interact with the respective macro realms and confirm the status quo. If the social actions are interpreted as a deviation from the cultural modes of behaviour, but only a minor and thus irrelevant deviation so that the social actors may still consider them to adhere to the unmarked format in a reasonable manner, the strategy "let it pass" is employed so that the procedure may follow the "et cetera" pattern. From a processing-effort viewpoint, any deviation requires more 'cognitive work', yet only an unreasonable deviation represents a marked format.

Should a social action deviate from the expected cultural mode of behaviour in an 'unreasonable' manner, the social actors have to account for the degree of deviation and they may either employ the "unless" strategy or practice "ad hocing" (Garfinkel 1994: 21). The "unless" strategy regulates the acceptance of a particular social action under specified conditions only. For this reason, it partly accepts its validity in the micro frame. In general, the contextualization of social actions, i.e. the attribution of explicatures or accounts to 
indexical actions, is carried out in the unmarked format. However, should an interpretation be inconsistent and therefore not hold, the status of the explicated presuppositions has to be reassessed. That is to say, the social actors have to make different explicatures (Sperber and Wilson 1996) so that the recontextualization of the respective indexicals may be licensed. From the discussion of these practices we can draw the conclusion that the relationship between micro and macro realms is represented by the explicatures of indexical social actions which give more explicit information about their contents as well as information about their communicative status, that is to say, what the content of the explicature counts as. The explicatures may also be accompanied by accounts, i.e. giving reasons and thus justifying why and for what purpose a speech act has been realized. Since there is always more than one explicature of a specific indexical, an account may also licence the attribution of relevance (Sperber \& Wilson 1996) to the respective presuppositions. After an explication of the interdependence of micro and macro realms, there is an investigation of the status of culture and its linguistic representation in an ethnomethodological framework.

If we accept the ethnomethodological premise that social reality is both result and process and is thus created in and through the process of communication, we also have to accept the entailment that the social construct of culture is created in a similar fashion. Therefore, culture also has to be investigated from macro and micro perspectives, as well as with regard to the interactive processes involved. Its analysis should, according to Harold Garfinkel, give special reference to "recognizing, using, and producing the orderly ways of cultural settings from "within" those settings" (1996: 31). This means that culture is a well-structured construct, which is interactionally organized. However, we do not generally communicate the phenomenon of culture in the explicit mode, but rather presuppose it: "much ... of what is actually reported is not mentioned" and yet the "unstated understandings" are "required" for the production and the interpretation of "recognizable sense" (1996: 10). That is to say, a speech act's presuppositions, i.e. its felicity conditions and other implicated premises and conclusions, are part of the socio-cultural knowledge of a speech community ${ }^{9}$ and thus not represented in the explicit mode in everyday life discourse but represented implicitly. But how do social actors get to know about those unstated understandings, and how do they know what unstated understandings to employ? In an ethnomethodology framework the knowledge about when, where and how to employ the appropriate contextual knowledge in order to fill in these gaps is part of the actors' sociocultural competence (Gumperz 1977). Not only do they know where and how to employ the strategy of gapping, but they also know where and how to retrieve the contextual information required in order to assign communicative meaning to these gaps. Furthermore, they know the culturally appropriate modes of encoding their messages, and they also know how to decode and/or infer the speaker-intended meaning, e.g. assertion or request. And how does the speaker know where s/he can employ gapping? And how does the hearer actually fill these gaps? Generally, a speech community's conventions explicate how a specific message, i.e. what is communicated, is to be encoded or decoded, and when and where the respective signals are appropriate. If we apply the paradigm of

\footnotetext{
${ }^{9}$ Generally, presuppositions and conversational implicatures are only explicated in so-called critical situations when there have been infelicities and other nonsuccesses.
} 
appropriateness to a contextualization approach, it means that a speech community's conventions explicate the degree of contextualization required for the appropriateness of an utterance. More specifically, the conventions instruct the members whether a specific message requires a higher or lower degree of explicitness. With regard to the message no thanks they tell us whether it is appropriate to produce the signals no, well, an interesting point of view or no way. These conventionalized modes of communication, which are also referred to as communicative strategies, will be discussed in the following section.

\section{Communicative strategies: preferred and dispreferred modes}

In the examination of propositional, interpersonal and interactional meaning: code and/or inference, natural-language communication is described as a rule-governed system in which the relation between internal message and external signal is governed by convention. However, does this conventional status of meaning apply to single words only (Andersson \& Hirsch 1985), or does it also refer to longer stretches of discourse? Generally, the meaning of a text is determined by the premise of compositionality, i.e. the meaning of its constituents, irrespective whether a bottom-up, top-down or their interaction is employed. This premise might hold for the investigation of a single sentence and its pragmatic realization as statement or request, but it certainly does not hold for the investigation of the discursive concepts of textuality and coherence. The more general notion of textuality and the more specific notion of coherence, which generally apply to one piece of discourse only, refer to the wellformedness of discourse and have generally been attributed a presuppositional status in discourse analysis. In an ethnomethodological framework, however, they are not only attributed a presuppositional status, since there is the additional premise which states that textuality and coherence are created in and through the process of communication. In the unmarked format they are realized by discourse connectives and other indexicals as well as by the macro concept of discourse topic and their respective subtopics. Textuality and coherence may also be realized by the employment of communicative strategies, which represent an even more specific means since they refer to the sequencing and wording of one speech event only.

Speech act theory and Grice's logic and conversation presuppose rational agents whose actions are performed with a specific speaker, respectively hearer intention (Grimshaw 1980). This principle of rationality covers the realms of propositional and illocutionary meaning. However, if the intention approach is applied to a discursive framework and its concepts of textuality and coherence, we have to account for speaker-intended textual, interpersonal and interactional meanings. Are they all transmitted with a specific speaker intention? There is no controversy in pragmatic research about speaker-intended textual meaning, yet there has been some controversy about speaker-intended interpersonal and speaker-intended interactional meanings. In contrast to the more traditionally oriented approach which has put interpersonal aspects of communication in the black box of phatic function(s) of language or phatic communication, Brown and Levinson's model person (1987) is defined by both rational face wants/needs and rational information wants/needs. Thus it integrates emotive aspects of communication (Janney \& Arndt 1992: 28) in their definition of rationality. This redefinition of a 
rational agent has implications on the definition of the concept of communicative strategy which not only guarantees efficient and effective modes for transmitting propositional information, but also the satisfaction of the participants' face wants and face needs. However, an investigation of communicative strategies cannot be restricted to a single speech act because the transmission of textual, interpersonal and interactional meanings frequently involves a sequence of utterances. Because of the premise of sequentiality, communicative strategies have to be investigated in discursive or conversation-analytic frameworks (Fetzer 2002). More specifically, their investigation has to accommodate the results of preference organization (Levinson 1983; Pommerantz 1984) and Lauerbach's reinterpretation of the dispreferred format (1993), which states that the additional language employed in the dispreferred format refers to the participants' face needs/wants. The phenomenon of additional language ${ }^{10}$ may also be attributed the function of an inference trigger, since it indicates an upcoming rejection which is frequently not explicitly realized, but conversationally implicated.

As a result, an investigation of communicative strategies has to be carried out in a framework in which language use is interpreted as social action, that is to say in which linguistic performance is characterized by a rational and intentional employment of language in a sociocultural setting. Second, linguistic performance does not apply to language output only and thus to the most efficient and most appropriate mode of representing a specific speaker intention, but it also includes the aspect of language input and the most efficient and most appropriate interpretation strategies. In other words, an investigation of communicative strategies has to account for the encoding and implicating of internal messages as well as for the decoding and inferring of the signals employed. Yet, communicative strategies do not only describe an appropriate employment of language, they also regulate and thus prescribe a socially accepted mode of verbal and nonverbal performance facilitating natural language communication since they provide the tools to perform and interpret a specific speaker intention, for instance a rejection, according to a speech community's cultural values. But how can communicative strategies be defined in a linguistic framework? From a linguistic viewpoint, communicative strategies can neither be attributed to the paradigms of grammatical and ungrammatical sentences, nor can they be attributed the paradigms of true or false propositions. And from a viewpoint of efficient communication, they do not necessarily represent the most efficient way of transmitting information and therefore do not have to adhere to the Gricean maxims of quantity, quality, relation and manner, but they certainly describe the most habitual, the most appropriate and thus the most accepted mode of performance. More specifically, from an interpersonal-communication viewpoint, they are linked to the linguistic representation of politeness and represent a means of transmitting the speaker's attitude to both her/his communication partner and her/his proposition which may, from an intercultural perspective, cause miscommunication. Since communicative strategies partly prescribe social actions with regard to their preferred modes, they may stabilize a speech community's cultural values. Should a speaker or a hearer not adhere to these preferred

\footnotetext{
10 The category of additional language is referred to as plus language in Fetzer (1996a/b) where a socio-semiotic approach to language is applied to a second-language-learning context.
} 
formats, s/he will generally not suffer any sanctions, for communicative strategies do not have a normative, but only a conventional status. Yet, any deviation from a speech community's preferred format will be evaluated as strange, since any deviation from a communicative strategy's preferred format is deliberate. ${ }^{11}$

Communicative strategies offer a promising field for investigating the phenomena of culture and cultural values since they are interdependent on social and cultural aspects of language as well as on the mental field of code and the social field of convention. From a preferenceorganization viewpoint, there are preferred and dispreferred modes, which entails that there exist less efficient and less appropriate modes of communication. Like the socio-semiotic approach to language (Halliday 1996), preference organization is based on the principle of linguistic variation. This means that internal messages or deep-structure meaning, for instance saying $N O$, may have more than one, if not an infinite number of linguistic realizations. However, the micro phenomenon of communicative strategy is not only characterized by internal factors, e.g. structural complexity, but also by external factors, e.g. the socio-cultural aspect of face and the institutional aspect of contextual constraints. Since communicative strategies are interdependent on social, cultural and mental domains, they are extremely complex and cannot be represented by discreet entities but have to be accounted for as a continuum with fuzzy boundaries. In the remaining part of this section I discuss possible linguistic realizations of the speech acts or communicative intentions of rejection and denial, i.e. saying $N O$, a social action which every human being is familiar with.

In the framework of speech act theory, saying NO is represented by the speech act of rejection, which rejects the illocutionary act, and the speech act of denial, which rejects a speech act's propositional content. From an interactional viewpoint, saying NO is anchored to the responsive format, and from an interpersonal viewpoint, it is characterized by a higher degree of face work than the complementary speech acts of agreement or acceptance. If speech act theory is adapted to a socio-semiotic framework, the production and interpretation of a speech act are not only interdependent on convention, but on a speech community's culture. This dual frame of reference is illustrated in an intercultural setting in which German native speakers analyse Anglo-American speech events with regard to the speech acts of acceptance and rejection. The data is adopted from Levinson (1983: 333, 334):

A Peter: It's brilliant this machine isn't it?

Dean: Yes it has a mind of its own.

Peter: That's also true.

If the investigation of the speech event is restricted to adjacency pair of assessment/response only, the German native speakers generally interpret Dean's response as agreement. The reason for this interpretation lies in the fact that firstly, there is the agreement token yes and secondly, that in the German cultural context the speech act agreement does not have to be boosted by, for instance, adverbials, in the preferred format (Fetzer 1994/96; Kalberg 1987;

\footnotetext{
11 Goffman's concept of virtual offence states that the non-communication of a friendly attitude indicates a hostile attitude (1974), and Edmondson claims that any surface (and non-surface) has to be attributed communicative significance (1983) .
} 
Kotthoff 1989). And even if Peter's response that's also true is added, the initial evaluation is hardly ever re-assessed.

B Peter: It's a beautiful day outside isn't it?

Dean: Yeah just gorgeous.

C Peter: It was too depressing.

Dean: Oh it is terrible.

Exchanges B and C usually do not cause any controversy since Dean's responses are interpreted as agreement. Yet, exchange D may create some controversy about the question whether it is possible to apply the same way of reasoning irrespective of the content of the assessment, for Peter's assessment I'm so dumb I don't even know it is face-threatening to the speaker himself. It consists of a self-deprecation, which, unlike the prior assessments requires a different response, i.e. a rejection, as a preferred reaction:

D Peter: I'm so dumb I don't even know it.

Dean: $Y$-no you're not dumb.

Exchange E deviates from the preferred format, but does not adhere to the dispreferred format either. It therefore triggers a process of inferencing resulting in an ironic reading:

E Peter: You're not bored.

Dean: Bored. No. We're fascinated.

Exchanges $\mathrm{F}$ and $\mathrm{G}$ display the nonverbal reaction of silence, which is very important in a socio-semiotic framework, since its interpretation is extremely interdependent on cultural preferences. Yet, silence is not only ambiguous in an intercultural setting, it is also ambiguous in an intracultural setting: it signals disagreement in $\mathrm{F}$ and agreement in $\mathrm{G}$ :

F Peter: God isn't it dreary!

Dean: silence

G Peter: I'm getting fat

Dean: silence

The following exchange is one of the most striking illustrations of the interdependence of cultural values and communicative strategies:

$\mathbf{S} \quad$ Uh if you'd care to come and visit a little while this morning I'll give you a cup of coffee.

H Ehm well that's awfully sweet of you. I don't think I can make it this morning. Ehm I'm running an ad in the paper and and I have to stay near the phone.

Not only does $\mathrm{S}$ employ several contextualization cues in order to attenuate the pragmatic force of her invitation, for instance the hesitation marker $u h$, the metapragmatic device if you'd care which refers to negative politeness (Brown \& Levinson 1987) and indicates the upcoming intrusion, and the downtoner a little while which further reduces its imposition. The participant $\mathrm{H}$ is even more elaborate with regard to her employment of hedging strategies: she firstly uses the hesitation marker ehm in order to delay her upcoming rejection. Secondly, there is the appreciation that's awfully sweet of you which further delays the 
rejection ${ }^{12}$ and only if the second part of the response, the mitigated rejection I don't think I can make it this morning and the account I'm running an ad in the paper and and I have to stay near the phone is displayed, do non-native speakers realize the speaker-intended meaning of rejection.

As a result, the appropriate interpretation of indexical expressions is part of a speech community's socio-cultural knowledge, which, in an ethnomethodological framework, indexes macro-cultural values. This change of perspective requires a discursive framework, which accommodates the phenomena of textuality, coherence, discourse genre, discourse identity, face, sequential status and indexicality. In the following section 'No thanks' revisited: the dialogue act 'plus/minus validity claim' the results of the discussion are systematized and applied to the definition of the dialogue act of a validity claim which is based on Habermas's approach to communication adapted to a socio-semiotic setting.

\section{5 'No thanks' revisited: the dialogue act 'plus/minus validity claim'}

In a language-as-a-linguistic-code framework internal messages are transformed to external signals and their relationship is determined by convention as is the case with the relationship between speaker intention and its linguistic representation, that is to say X counts as Y. But is language still represented appropriately in a code model if the realm of application is extended to longer stretches of discourse such as phrases and texts? And how does a code model account for the interdependence between a speech community's habitus (Kress 1996), and its social code and practice?

Natural-language communication is characterized by linguistic variation and thus by preferred and dispreferred modes for representing a specific speaker intention. In conversation analysis, preference organization has been employed in the investigation of adjacency pairs, but there is no reason why it cannot be applied to an utterance's degree of explicitness with respect to the linguistic representation of a speaker intention. An account of implicit meaning requires a change of frame and thus the explicit accommodation of context and contextualization. The dialogue act of a plus/minus validity claim adapts the concept of presupposition to both language-internal and language-external constraints and demands by categorizing context in an interactive tripartite system of objective, social and subjective worlds and their respective presuppositions (Fetzer 1994, 1996, 1997):

\footnotetext{
12 If this exchange is investigated up to this point only, German native speakers usually interpret H's response as acceptance.
} 
figure I:

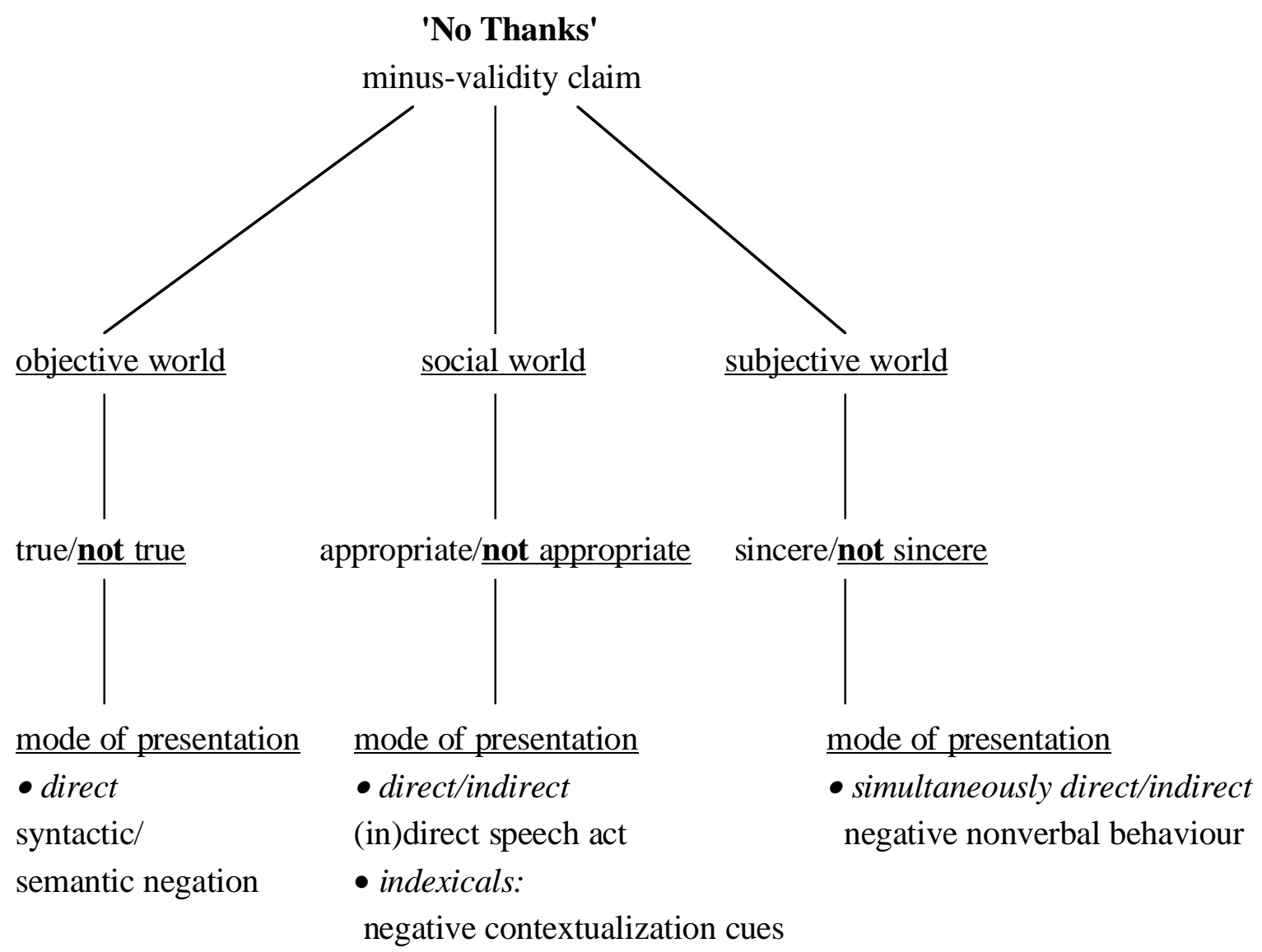

The objective world is defined by the paradigm of true/false. Validity claims set in this framework state the truth or non-truth, refer to a validity claim's theoretical claim(s) or proposition(s) and can only be represented in the direct or explicit mode by syntactic and/or semantic negation. The second base of the dialogue act of a plus/minus validity claim, the social world, is defined by the paradigm of appropriateness, which is interdependent on the appropriateness of the interpersonal, interactional and textual presuppositions. The social world refers to the communicative function of the speech act based on the proposition and can be represented both in the explicit and/or implicit/indexical mode. The third pillar, the subjective world, is defined by the paradigm of sincerity, i.e. speaker intention meant as uttered, and is represented in the simultaneously explicit and implicit mode. Yet how may this theoretical framework account for the phenomenon of culture? Is culture part of the objective, social or subjective worlds?

The objective world is determined by the dichotomy true/false and may therefore only partly account for the cultural filter which regulates the interpretation of reality which is manifest in Garfinkel's (1996: 68) concept of cultural dope, and thus represents a stabilizing factor. Because of this metaperspective, culture has to be attributed to the social and subjective worlds, which are defined by the additional filter of convention. Let me illustrate this claim with the nonverbal act of smiling, which may be attributed to the subjective world since it is 
represented simultaneously explicitly and implicitly. Yet the actual interpretation of a social act as an act of smiling depends on the conventions of a specific speech community, which regulate whether a combination of movements of mouth, eyes and cheeks realizes an act of smiling or whether it instantiates an act of laughing or grinning. The combination of the nonverbal act of smiling and the verbal act of saying no thanks may be quite appropriate in some cultural contexts, e.g. in the Far East, whereas it is considered to be quite inappropriate in most Anglo-American and German settings, in which it may result in the attribution of an insincere speaker intention.

In the following the social world, which is also anchored to a tripartite system, is discussed and special reference is given to its accommodation of culture and cultural values:

figure II:

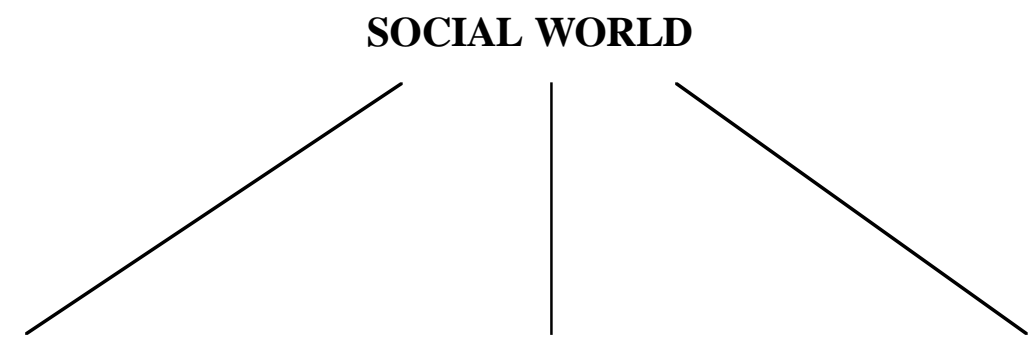

textualframe

$$
\mid
$$

Gricean CP interpersonal frame

$$
\mid
$$

participation format/ interactional frame

$$
\mid
$$

sequential organization

\section{face-orientation}

The social world represents another tripartite system of textual, interpersonal and interactional frames and their respective presuppositions. The textual frame is governed by the Gricean Cooperative Principle, the maxims of quality, quantity, manner and relation, and the conversational implicature. It is represented explicitly by direct speech acts, and implicitly by indirect speech acts and the indexicals more-fuzzy and less-fuzzy hedges. The retrieval of the speaker intention and her/his speaker-intended conversationally implicated meaning depends to a large extent on these inference triggers and other illocutionary force indicating devices. The interpersonal frame is governed by participation format, i.e. the role/function of (un)ratified participants, and face, which, should they be represented indexically, also have to be retrieved through a process of inferencing. The interactional frame is determined by sequential organization, which is based on the concept of adjacency, i.e. adjacency pair, 
adjacency relation and adjacency position. In the following, this theoretical framework is applied to actual language data, more specifically to saying no thanks, which will be investigated with regard to explicit and implicit representations.

The explication of one or more of an utterance's presuppositions generally implies their rejection, as is the case with example (5), which rejects one of its textual presuppositions, the Gricean maxim of relation:

(5) This is not relevant/Das ist nicht relevant.

A rejection of the interpersonal presuppositions, i.e. participation format and face wants/needs, may be realized by

(6) I have not been talking to you as the teacher Thomas Cook, but to you as my husband Thomas Cookl

Ich rede nicht mit dir in deiner Funktion als Lehrer, sondern als Ehemann.

(7) Don't be so touchy/sei nicht so empfindlich.

Example (6) explicates two possible discourse identities of an individual and rejects the participant's momentary role in the participation format, while example (7) refers to a participant's excessive face wants. A rejection of the interactional presuppositions may be realized by

(8) Stop interrupting me, it's not your turn yet/

Unterbrich mich nicht, du kommst erst später an die Reihe.

Example (8) explicates inappropriate interactional presuppositions with regard to the turntaking system, i.e. the inappropriate self-selection, which is closely connected to the participation format. Whereas a participant's (un)ratified discourse identity is attributed to the interpersonal frame, her/his instantiation with regard to the turn-taking system is set in the framework of the interactional presuppositions.

From a discourse-distribution viewpoint, the explicit rejections in (5), (6), (7) and (8) have to be attributed a marked status in both the Anglo-American and German context for they are generally restricted to argumentative settings in which the argumentation escalates. In other words, it seems far more 'natural', far more 'conventional' to employ negative contextualization cues for the rejection of prior discourse despite the fact that their communicative meaning depends to a large extent on the socio-cultural conventions of a speech community. ${ }^{13}$ In the following negative contextualiaztion cues are categorized with regard to their references to the textual, interpersonal and interactional frames:

\footnotetext{
13 The attribution of formality or informality to a communicative encounter may depend on the distribution of specific contextualization cues. For example, in French the employment of the indexicals alors, bien, and bon ben attributes informality to a setting, which is not the case with the English indexicals well or but. However, some indexicals have a genre-specific distribution - I am referring to spoken settings only.
} 
figure III:

\section{social world: indexical representation}

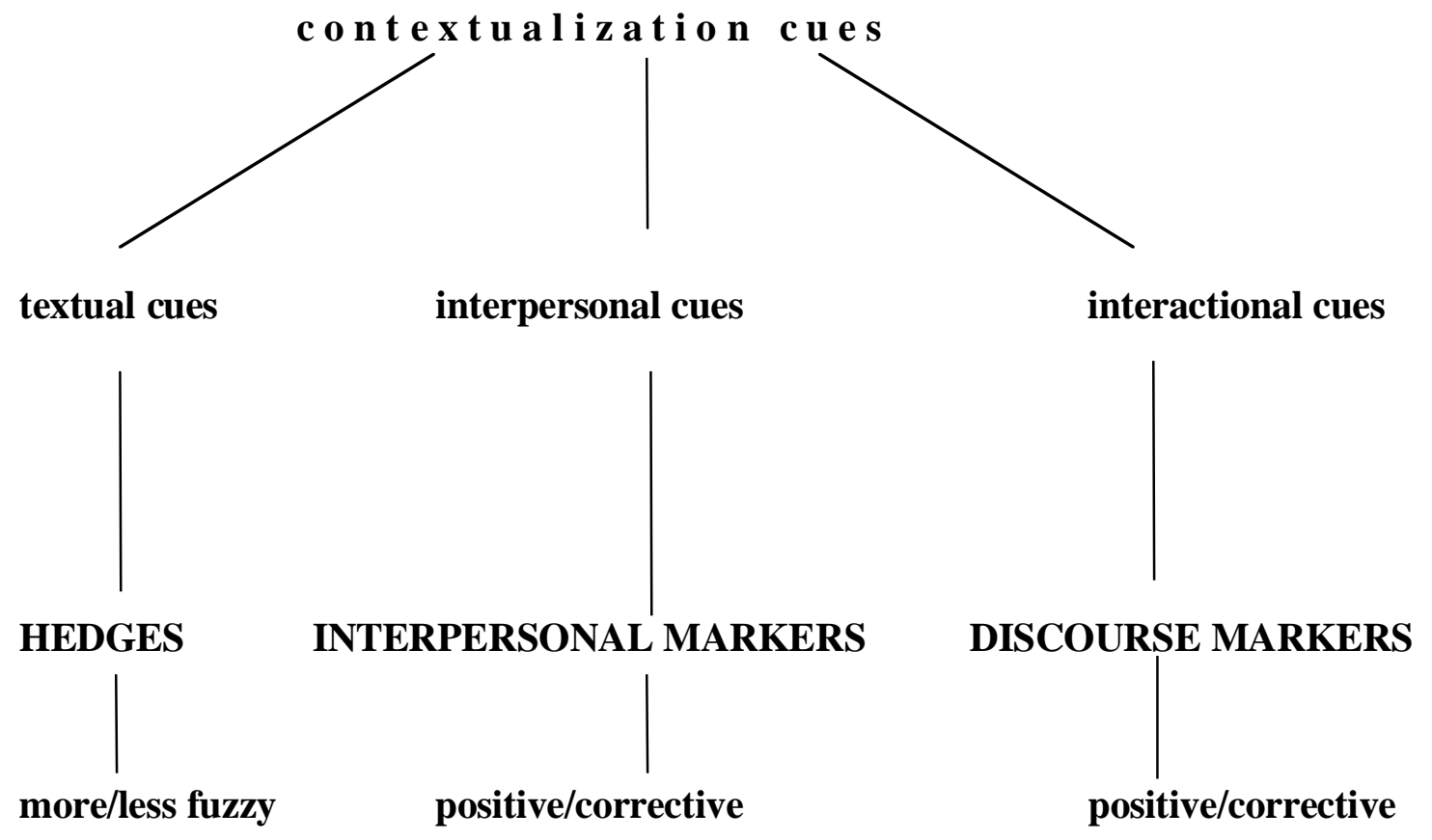

Negative contextualization cues are not only frequently employed in mundane face-to-face interactions, but also in institutional discourse, e.g. political interviews and student-lecturer interactions. An indexical realization of no thanks rejecting textual presuppositions can be represented by more-fuzzy hedges, which attenuate the pragmatic force of the rejection, e.g. kind of/sort of or somehow or it can be realized by less-fuzzy hedges, which boost the pragmatic force of the rejection, e.g. to say it straight away, frankly, bluntly, in fact or actually. A cross-cultural investigation of the distribution of negative contextualization cues in the genre of a political interview (Fetzer 1994) in German and British contexts came to the conclusion that the Anglo-American context prefers a larger degree of attenuation. More specifically, in the German context discussed, both interviewer and interviewee realize their rejections on record and additionally boost the pragmatic force, ${ }^{14}$ whereas the British interviews generally employ an off-record strategy for the linguistic representation of the rejection or redress it with the more-fuzzy hedge sort of. The interpersonal frame has to be differentiated with regard to references to the speaker and hearer-oriented presuppositions, which may either attenuate or boost the negative pragmatic force. Speaker-oriented indexicals are, e.g. I must say, let me, if I might, I may say, forgive me, in my view, I think/mean/suppose or as far as I can see whereas hearer-oriented strategies are realized by indexicals referring to the hearer's face wants, e.g. with all due respect, apologies, e.g. I am sorry and

\footnotetext{
14 In the genre of a political interview, the majority of rejections were not only performed on record, but also boosted by adverbials, e.g. ja aber das stimmt DOCH nicht, das entspricht nicht den Tatsachen or die Frage werde ich SO nicht beantworten. Similar results are obtained with the cross-cultural investigation of studentlecturer interactions. In the German context the explicit rejection nee nee is frequently employed, whereas in the Anglo-American setting there is the interpersonally-oriented strategy I think you want or what you want is.
} 
reformulations. Additionally there is the explicit negative reference to the speaker-oriented interpersonal presuppositions, which frequently employ transferred negation, e.g. I'm NOT going to and I doN'T think. The most frequent indexicals of the interactional frame are represented by the negative discourse markers well and but and the hesitation marker erm.

The dialogue act of a validity claim may not only account for a speech community's preferred and dispreferred modes of representing rejections from an intra- and interlingual viewpoint, but it may also accommodate a multitude of communicative settings and thus account for a speech community's and various subcommunities' socio-cultural values. However, communicative strategies for language production and language interpretation apply to the socio-cultural values of the respective speech community only and are thus part of its language game - their communicative value may be quite different in another community.

\section{Conclusion}

Natural language communication is extremely complex and feeds on a multitude of languageexternal factors, such as social structure, speaker, hearer and cultural context. All of these external factors have a decisive influence on the communicative encounter, but the most important constituents are the participants and their respective discourse identities. In a sociocultural setting, both speakers and hearers represent rational agents with a speaker, respectively hearer intention, and they perform social actions and thus act strategically in order to achieve their communicative goals, e.g. saying no.

However, rational agents do not only have information wants and information needs, they also have face wants and face needs. This dual frame of reference requires a redefinition of rationality since it has to account for the participant's sociocultural competence and thus her/his ability to perform social actions appropriately. Yet natural language communication is not only interdependent on external, but also on internal factors, i.e. on the linguistic code's phonological, morphological, syntactic and semantic modules and respective constituents, whose instantiation and combination offer an almost infinite number of possibilities for the linguistic representation of speaker-intended meaning by accommodating the participants' face and information wants/needs as well as other relevant contextual constraints.

A socio-semiotic approach to language is based on the principle of linguistic variation, i.e. on preferred and dispreferred modes for the representation of a specific communicative intention, may thus account for both language-internal and language-external factors. However, linguistic variation is not based on random decisions, but rule-governed with regard to e.g. an utterance's degree of explicitness or formality. The underlying rules and regularities are part of the rational agent's sociocultural competence. That is to say, the agent chooses one and only one linguistic surface for the realization of her/his speaker intention in order to create as well as define the sociocultural context of the communicative encounter. The respective decision-making processes involve "judgmental work of the user" (Garfinkel 1996: 71), for s/he has to account for the addressee's face and/or information wants when mapping deepstructure meaning to an appropriate surface. Yet it is not only the individual actor who 
decides which surface is appropriate since any individual member of a speech community 'knows' its social code and social practice.

This dual frame of reference is not only reflected in the individual's face and information wants, but also in the ethnomethodological perspective of micro and macro realms, and thus anchors the investigation of language output and language input to a framework in which both context and culture are created in and through the process of communication: "Sociologically speaking, "common culture" refers to the socially sanctioned grounds of inference and action that people use in their everyday affairs and which they assume that others use in the same way“ (Garfinkel 1996: 76). As a result, an ethnomethodological approach to communication cannot be restricted to the investigation of single speech acts, but requires a discursive framework based on the premise of reflexibility with regard to internal and external factors as well as with regard to their interaction. Thus, the linguistic code and the social practice must be firmly anchored to a theoretical framework which has to account for both context and culture.

The dialogue act of a plus/minus validity claim accommodates all of these requirements by anchoring natural language communication to an interactive tripartite system of objective, subjective and social worlds and their respective presuppositions. In this setting, communicative strategies represent a speech community's social code with regard to its preferred and dispreferred modes of language output, language input and the respective coding and inference processes involved, which cannot be carried out without any references to common sense knowledge. Culture-specific interpretations of linguistic surface structures have been illustrated by an intra- and intercultural investigation of the speech event saying no in the framework of the dialogue act of a minus-validity claim. The investigations have demonstrated that implicit modes of representing speaker-intended meaning as well as negative contextualization cues are interdependent on a speech community's social code and thus culture-specific. The indexicals may even be attributed the status of a metaphor for the spoken mode.

A socio-semiotic approach to language supplemented by ethnomethodological principles does not only account for the 'semiotics' of language in a macro framework, but also for their social practice in a micro setting by focussing on the interdependencies of social, cultural and mental perspectives, thus anchoring culture and cultural information to the presentation of self in everyday life (Goffman 1971).

\section{References}

Atkinson, John/Heritage, John (eds.) (1984): Structures of social action. Cambridge.

Andersson, Lars-Gunnar/Hirsch, Richard (1985): Swearing. Report No 2. Göteborg.

Auer, Peter/DiLuzio, Aldo (eds.) (1992): The contextualization of language. Amsterdam.

Biber, Douglas (1988): Variations across Speech and Writing. Cambridge.

Blum-Kulka, Shoshana (1987): "Indirectness and politeness in requests: same or different?". JoP 11: 131-146.

Brown, Penelope/Levinson, Stephen (1987): Politeness. Cambridge. 
Coulmas, Florian (ed.) (1981): Conversational routine. The Hague.

Dijk, Teun A. van (ed.) (1985): Handbook of discourse analysis. New York.

Duranti, Alessandro/Goodwin, Charles (eds.) (1992): Rethinking Context. Cambridge.

Edmondson, Willis (1983): "A Communication Course for German Teachers of English". Dialoganalyse und Sprechfertigkeit (Amsterdamer Werkheft). München: 25-36

Edmondson, Willis/House, Juliane/Kasper, Gabriele/Stemmer, Brigitte (1984): "Learning the pragmatics of discourse: a project report". AppL 5(2): 113-127.

Fetzer, Anita (1994): Negative Interaktionen: kommunikative Strategien im britischen Englisch und interkulturelle Inferenzen. Frankfurt.

Fetzer, Anita (1996a): "Preference organization and interactive language teaching. Communicative strategies in a German-English context". IRAL XXXIV/2: 77-93.

Fetzer, Anita (1996b): "Preference organization und Sprechfertigkeit im engl.-dt. Kontext. Vom propositionalen Schlagabtausch zur interkulturellen Kompetenz". GAL Bulletin 24/2: 63-80.

Fetzer, Anita (1997a): "Konversationsanalyse und Konversationsunterricht". Zeitschrift für Interkulturellen Fremdsprachenunterricht. [online] Jg. 2, Heft1: http://www.ualberta.ca/ german/ejournal/-ejournal.html.

Fetzer, Anita (1997b): "Recontextualizing context". ECCS '97. Conference Proceedings. European Conference on Cognitive Science. April 9-11, 1997. Manchester UK: 176-180.

Fetzer, Anita (1997c): "Negative contextualization: a socio-semiotic approach to language teaching". In: Pütz, Martin (ed.): The cultural context in foreign language teaching. Frankfurt: 85-109.

Fetzer, Anita (1998): "NEIN-SAGEN". In: Pittner, Robert/Pittner, Karin (eds.): Beiträge zu Sprache \& Sprachen, 5. Münchener Linguistik Tage. München: 183-191.

Fetzer, Anita (2000): "Polite rejections: teaching interpersonal communication skills". In: Dakowska, Maria (ed.): English in the Modern World. Frankfurt: 41-54.

Fetzer, Anita (2001): "Kontextualisierung im nicht-präferierten Format". In: Pittner, Robert/ Pittner, Karin (eds.): Beiträge zu Sprache \& Sprachen, 6. Münchener Linguistik Tage. München: 153-160.

Fetzer, Anita (2002): "Communicative intentions in context". In: Fetzer, Anita/Meierkord, Christiane (eds.): Rethinking sequentiality: linguistics meets conversational interaction. Amsterdam: 37-69.

Franck, Dorothea (1979): Grammatik und Konversation. Amsterdam.

Fraser, Bruce (1990): "Perspectives on politeness". Journal of Pragmatics 14: 219-236.

Garfinkel, Harold (1996): Studies in ethnomethodology. Cambridge.

Givon, Tom (1993): English Grammar: a function-based introduction. Amsterdam.

Goffman, Erving (1971): The presentation of self in everyday life. Harmondsworth.

Goffman, Erving (1974): Frame analysis. Boston.

Grice, Herbert P. (1975): "Logic and conversation". In: Cole, Martin/Morgan, Jerry (eds.): Syntax and Semantics. New York: 41-58.

Grimshaw, Allan (1980): "Mishearings, misunderstandings, and other nonsuccesses in talk". Sociological Inquiry 50: 31-74. 
Gumperz, John (1977): "Sociocultural Knowledge in Conversational Inference". In: SavilleTroike, Muriel (ed.): Linguistics and Anthropology. Washington DC: 191-211.

Gumperz, John (ed.) (1982): Language and social identity. New York.

Habermas, Jürgen (1987): Theorie des kommunikativen Handelns. Frankfurt.

Hall, Eduard/Hall, Mildred (1994): Understanding cultural differences. Yarmoth.

Halliday, Michael (1996): Introduction to functional grammar. London.

Heritage, John (1992): Garfinkel and ethnomethodology. Cambridge.

Holly, Werner (1990): Politikersprache. Berlin.

Holly, Werner (1992): "Was Kohl kann, was Krenz nicht konnte". In: Dyck, Jürgen et al.(eds.): Rhetorik. Tübingen: 33-50.

Janney, Richard/Arndt , Horst (1992): "Intracultural tact versus intercultural tact". In: Watts, Richard et al.: Politeness. Berlin: 21-41.

Kalberg, Stephen (1987): "West German and American Interaction Forms: one Level of Structured Misunderstanding". Theory, Culture \& Society 4: 603-618.

Kotthoff, Helga (1989): Pro und Kontra in der Fremdsprache. Frankfurt.

Kress, Günther (1996): "Representational resources and the production of subjectivity". In: Caldas-Coulthard, Maria/Coulthard, Malcolm (eds.): Texts and practices. London: 15-31.

Lakoff, George/Johnson, Mark (1980): Metaphors we live by. Chicago.

Lauerbach, Gerda (1993): "Conversation analysis and its discontent". In: Goebel, Walter/ Seeber, Hans (eds.): Anglistentag 1992. Tübingen: 427-436.

Leech, Geoffrey (1983): Principles of pragmatics. London.

Levinson, Stephen (1983): Pragmatics. Cambridge.

Pomerantz, Anita (1984): "Agreeing and disagreeing with assessments: some features of preferred/dispreferred turn shapes". In: Atkinson, John/Heritage, John (eds.): Structures of social action. Cambridge: 57-101.

Posner, Roland (1989): "What is culture? Toward a semiotic explication of anthropological concepts". In: Koch, Walter (ed.): The nature of culture. Bochum: 240-295.

Schiffrin, Deborah (1987) : Discourse markers. Cambridge.

Searle, John (1969): Speech Acts. Cambridge.

Sonesson, Göran (1989): Pictorial concepts: inquiries into the semiotic heritage and its relevance to the interpretation of the visual world. Lund.

Sperber, Dan/Wilson, Deidre (1996): Relevance. Oxford.

Thomas, Jenny (1985): "The language of power. Towards a dynamic pragmatics". Journal of Pragmatics 9: 765-783.

Tottie, Gunnel (1991): Negation in English speech and writing. London.

Verschueren, Jef/Bertuccelli-Papi, Marcella (eds.) (1987): The pragmatic perspective. Amsterdam.

Watts, Richard et al. (eds.) (1992): Politeness in Language. Berlin.

Wierzbicka, Anna (1991): Cross-Cultural Pragmatics: the Semantics of Human Interaction. Berlin.

Wilson, John (1990): Politically speaking. Oxford. 